\title{
BMJ Open Mixed-method evaluation of a community-based postpartum support program: a study protocol
}

\author{
Josephine Etowa, ${ }^{1}$ Amy Johnston (D) ${ }^{2,3}$ Zahra Jama, ${ }^{1}$ Kristin M Eccles, ${ }^{4}$ \\ Alicia Ashton ${ }^{5}$
}

To cite: Etowa J, Johnston A, Jama Z, et al. Mixedmethod evaluation of a community-based postpartum support program: a study protocol. BMJ Open 2020;10:e036749. doi:10.1136/ bmjopen-2019-036749

- Prepublication history and additional material for this paper are available online. To view these files, please visit the journal online (http://dx.doi. org/10.1136/bmjopen-2019036749).

Received 31 December 2019

Revised 11 August 2020

Accepted 12 August 2020

Check for updates

(C) Author(s) (or their employer(s)) 2020. Re-use permitted under CC BY-NC. No commercial re-use. See rights and permissions. Published by BMJ.

${ }^{1}$ School of Nursing, Faculty of Health Sciences, University of Ottawa, Ottawa, Ontario, Canada ${ }^{2}$ School of Epidemiology and Public Health, Faculty of Medicine, University of Ottawa, Ottawa, Ontario, Canada ${ }^{3}$ Brain and Heart Nexus Research Program, University of Ottawa Heart Institute, Ottawa, Ontario, Canada

${ }^{4}$ Department of Geography, University of TorontoMississauga, Mississauga, Ontario, Canada

${ }^{5}$ Mothercraft Ottawa, Ottawa, Ontario, Canada

Correspondence to Dr Josephine Etowa; jetowa@uottawa.ca

\section{ABSTRACT}

Introduction Becoming a parent is one of the most significant events an individual will experience in their lifetime. The postpartum period can be a difficult time, especially for mothers, who may require extra support during this challenging time. The proposed study seeks to understand the issue of postpartum support for mothers and their families. It will address this aim by using the Mothercraft Ottawa Postpartum Support Drop-in Program as real-life illustration of a community-based service organisation delivering these services.

Methods and analysis A three-phased mixed-method programme evaluation guided by the Reach, Effectiveness, Adoption, Implementation, and Maintenance (RE-AIM) evaluation framework and the tenets of communitybased participatory research. Instrumental case study methodology will be employed to gain an in-depth understanding of what impact(s) the programme is having on mothers, their partners and their families (phase Iqualitative). A questionnaire, regression modelling, and geospatial analysis will be conducted to gain a deeper understanding of specific programme outputs and to generate information that will help inform programme reach (phase II-quantitative). Study phase III will focus on knowledge translation activities to stakeholders and the broader academic community.

Ethics and dissemination Ethics approval was granted by the University of Ottawa Research Ethics Board $(\mathrm{H}-12$ 18-1492). The results of this study will be disseminated at a community workshop, in an academic thesis, at academic conferences and in peer-reviewed publications.

\section{INTRODUCTION}

Mental health difficulties are relatively common during the perinatal period and can have lasting negative impacts on infant development, childhood behaviour and the family unit. $^{1-6}$ The physical, biological, emotional and social changes experienced by women in the postpartum period makes them especially vulnerable to any one or a combination of mood and anxiety disorders that fall on a wide spectrum of 'postpartum phenomenology' (eg, anxiety, obsessive compulsive disorder, panic disorder and postpartum depression (PPD) $).{ }^{37}$ Several factors increase the risk of

\section{Strengths and limitations of this study}

The study will employ a mixed-method evaluation to increase its scope and enhance the breadth and depth of our findings.

- We will include a heterogenous population that encompasses mothers, their partners and key stakeholders to gain a rich understanding of the phenomena of interest.

- This study will be guided by the Reach, Effectiveness, Adoption, Implementation, and Maintenance (REAIM) evaluation framework and will follow the tenets of community-based participatory research.

- Measures of programme 'success' will be based on participant experience rather than clinical measures.

- Participants will be recruited through a first-come first-served basis; thus, participant cohorts may not necessarily constitute a representative sample.

developing mental health challenges such as a history of depression or anxiety, a difficult birth, maternal or child medical issues, social isolation, not feeling supported and recent life stress. ${ }^{8}$

The WHO estimates that, globally, approximately $10 \%$ of pregnant women, and $13 \%$ of those postpartum, experience a mental health disorder. ${ }^{9}$ Further, a recent Canadian survey of postpartum women revealed that between $16 \%$ and $31 \%$ of mother had feelings consistent with an anxiety disorder or PPD. ${ }^{10}$ Others studies suggest that an even higher percentage of women face social, relationship, identity and self-efficacy challenges during the postpartum period. ${ }^{311} 12$ Despite being relatively common, evidence suggests that anxiety and mental illness experienced during the perinatal period are both underdiagnosed and undertreated..$^{13}$ The stigma associated with postpartum anxiety and mood disorders, in addition to the perception that others might view these challenges as a 'failing' of motherhood, may be key contributing factors. ${ }^{3} 14$ 
Given the severe consequences that postpartum anxiety and mood disorders can have on maternal and infant health, well-being and development, programmes designed to address and alleviate symptoms are a public health priority. To better understand the state of postpartum mental health services in Ottawa, Ontario, the Champlain Maternal Newborn Regional Program (CMNRP) conducted a review of available programming and resources. ${ }^{15}$ Of the services available for women facing postpartum mental health challenges, the CMNRP concluded that the Mothercraft Postpartum Support Drop-In Program (currently operating out of two Ottawabased locations) was the only free, self-referred and facilitated peer-support group available. Other programmes identified were individual or group counselling sessions and were usually offered at a cost.

The Mothercraft Program's drop-in format lowers barriers to access such as cost and a mental health diagnosis as participants attend the programme by selfreferral. While a mental health diagnosis is not required to attend, the programme's activities have helped some mothers seek formal medical assistance and mental health support. The programme has sought to reduce social isolation associated with early motherhood, decrease stigma and increase access to community resources and peer support. Further, participants do not need to be active participants in the group if they do not feel comfortable doing so and can attend as many or as few sessions as they feel necessary.

Since its inception in 2013, many anecdotal benefits of this programme have been noted including one mother stating that the programme 'saved her life'. Other feedback suggests that mothers have formed partnerships of mutual support to decrease their social isolation, were able to leave the house more comfortably with their infants and began attending other social programming because they attended the programme. While the anecdotal benefits of the Mothercraft Postpartum Support Drop-in Program are abundant, a formal evaluation is required to gain a better understanding of what impacts the programme is having on the health and well-being of attendees and their families.

\section{STUDY PURPOSE AND OBJECTIVES}

The purpose of this study is to explore the experiences of postpartum women who have attended the Mothercraft Postpartum Drop-in Support Program, with the following specific aims:

1. To describe the experiences of women who have attended the programme.

2. To assess the programme's overall effectiveness in providing support to attendees.

3. To identify facilitators and barriers to programme utilisation.

4. To generate knowledge that can help improve the current programme and inform the development of future programming.

\section{SIGNIFICANCE}

Mothercraft Ottawa will use the results of this evaluation to (1) validate programme strengths and maintain the critical programme components, (2) update the programme to address gaps and emphasise its strengths, (3) support funding applications for sustainable programme expansion to serve a broader clientele across the city of Ottawa and (4) inform the development of a comprehensive service expansion of a broader perinatal mental health programme.

\section{METHODS AND ANALYSIS}

We will conduct a mixed-method ${ }^{16}$ evaluation of the Mothercraft Postpartum Support Drop-in Program to generate information about participants' experiences and assess the programme's overall effectiveness. This study will be conducted by an all-women multidisciplinary team that consists of perinatal health professionals (registered nurses AA, ZJ and JE), researchers (ZJ, JE, AJ, KE) and community developers (AA and JE) who have varying degrees of experience working with postpartum women and their families. As illustrated in figure 1, this research will be carried out in three unique but interconnected phases. In the first two study phases, we will employ of qualitative (phase I) and quantitative (phase II) methods to directly address the study's specific aims. In phase III of the study, we will focus on translating the knowledge gained from the proposed study to direct stakeholders and the broader academic community. Data collection began in July 2019 and the study is expected to be completed before the end of 2020.

\section{Conceptual framework}

The Reach, Effectiveness, Adoption, Implementation, and Maintenance (RE-AIM) framework ${ }^{17}$ will be used as a guide for carrying out phases I and II of this research. ${ }^{18}$ All phases will be carried out in keeping with the tenets of community-based participatory research (CBPR). ${ }^{19}$ CBPR is a process of critical and social action inquiry that promotes participation of people, organisations and communities towards a mutual goal of effecting change. ${ }^{19-22}$ This is especially true when assessing the impact of programmes designed to serve vulnerable populations. ${ }^{22}$ With its origins from the work of Paulo Freire in the $1970 \mathrm{~s},{ }^{23}$ CBPR emphasises consciousness-raising, participation, capacity building, ownership of knowledge and empowerment of those being studied. ${ }^{19}$ The CBPR process helps create links between the best of science and point-of-care practice as community members are mobilised to codiscover, codesign and implement solutions to the problems and challenges of their community. For example, while the community partners who initiated this project determine their level of participation, they have been instrumental in the design and implementation of each phase of the project. CBPR principles value the community member expertise and enables people to collectively tackle complex community issues by 


\section{COMMUNITY-BASED PARTICIPATORY RESEARCH}
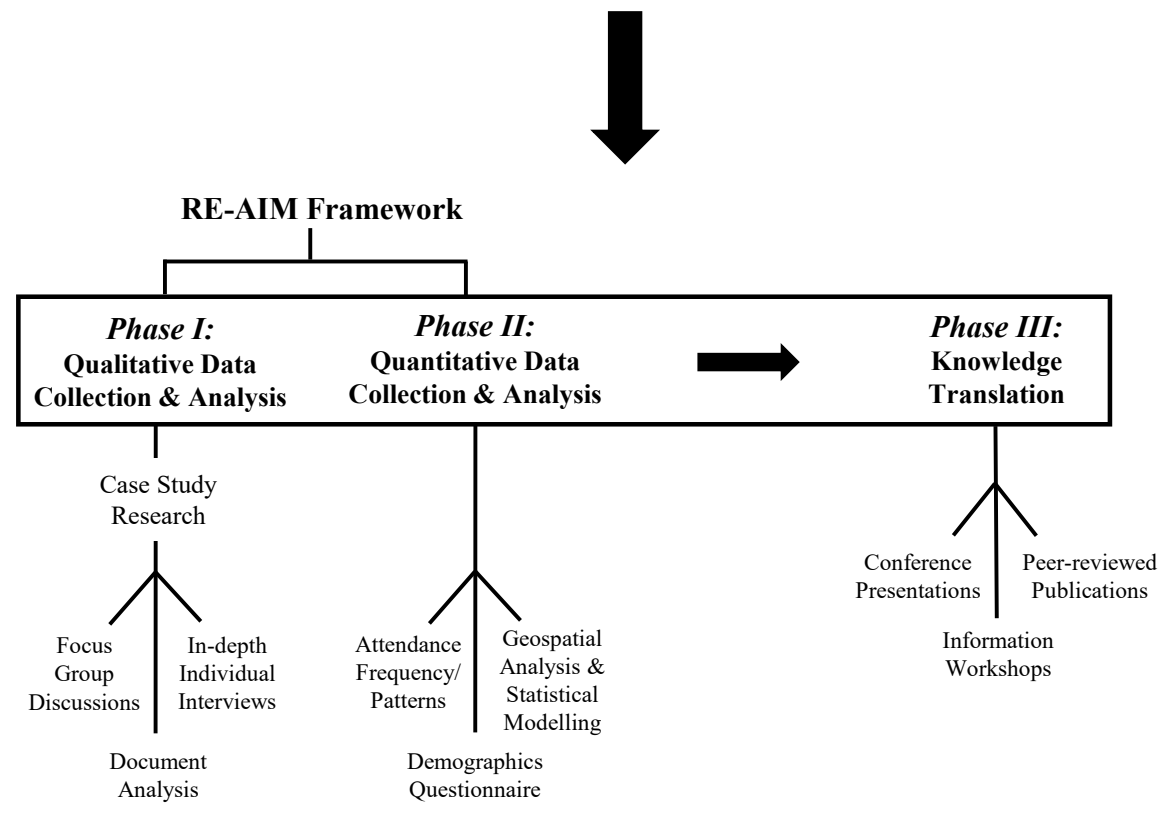

Figure 1 Conceptual framework outlining the general frameworks guiding this research, each of the three study phases and the methodology used to undertake each phase.

themselves, with local means, talents and all other available means. 202425

\section{Patient and public involvement}

This collaborative study partnership study is strongly rooted in the principles of CBPR. ${ }^{21}{ }^{22} \mathrm{It}$ was initiated by community partners, which included Mothercraft organisational leadership as well as a programme participant, who invited academic partners to examine this area of need in the community. The proposed study will be co-led by the community partner/knowledge user (Co-Principal Investigator, AA) and all (community and academic) stakeholders have been integrally involved in developing and refining the research aims and objectives. Study participants will be asked to assist with recruitment through word of mouth (snowball technique). While a formal local advisory group was not created because this is an unfunded study with limited resources, the community members have been a useful source of information about the area surrounding the Mothercraft facility and the nature of its programmes. Such information has been instrumental in the design and timing of our project activities including the scheduling of interviews and our planned knowledge translation activities. This level of collaborative engagement will continue throughout all phases of this research to ensure meaningful involvement of all partners in decision-making related to study activities.

\section{Research phases I and II}

Table 1 outlines the specific objectives and research questions to be addressed in study phases I and II. As illustrated in figure 1, and explained in more detail as follows, study phase I will employ the Robert Stake instrumental case study research approach, ${ }^{26}$ which will facilitate the development of a rich description of the 'case' (Mothercraft Ottawa). In phase II, we will analyse the results of a questionnaire and perform a geospatial analysis to gain a deeper understanding of specific programme outputs and generate information that will help inform programme reach.

\section{The RE-AIM evaluation framework}

The overall impact of a public health programme cannot be determined based on clinical effectiveness alone and multiple elements should be considered. ${ }^{18}$ Glasgow et al ${ }^{18}$ developed the RE-AIM programme evaluation framework, which asserts that five factors, including: reach, effectiveness, adoption, implementation and maintenance can be used to validate and measure programme impact as well as its transferability. ${ }^{1718}$ RE-AIM is detailed enough to comprehensively review a programme in its entirety, yet broad enough in its scope to allow for new knowledge to emerge unhindered. ${ }^{18}$ It is a framework that guides stakeholders and researchers to understand and examine the internal and external factors that help and hinder a programme's success.

\section{Study phase I: case study research}

The intent of this research is to understand the issue of postpartum support for mothers and their families and will use a community-based service organisation as a reallife illustration. In keeping with the principles of instrumental case study approach, ${ }^{26}$ this research will focus 
Table 1 Data collection phases, objectives, questions addressed and activities to be performed

\section{Research phase: paradigm}

Phase I: qualitative data collection

Phase II: quantitative data collection

\section{Objectives}

Describe the experience of programme participants and identify barriers and facilitators that influence programme use Gain an understanding of the perspectives of care providers and key stakeholders of the programme.

\section{Research questions (RQs) to be} addressed

$R Q 1$. How do participants define programme 'success'?

RQ2. Do participants consider the services provided by the programme to be valuable? If so, what were the programme's 'valuable' attributes? RQ3. Are participants satisfied with the programme? Why or why not? RQ4. Are there external factors that influenced participants' ability to attend the programme? If so, what are they?

Measure and report on specific programme outputs (eg, number of participants, their characteristics) related to programme reach to generate information that will improve service provision and inform programme development.
RQ5. How many participants participate in the programme each week? Has this changed over time?

RQ6. How many times do participants attend the programme before stopping?

RQ7. How far do participants travel to participate?

RQ8. What are the general demographic and socioeconomic characteristics of participants? RQ9. What proportion of eligible participants have participated in the programme?

RQ10. Would the city of Ottawa benefit from a similar programme in other location(s) in the city? on a single organisation where women seek postpartum support (ie, Mothercraft Ottawa). As an instrumental case, the Mothercraft organisation will be critically examined for how commitment to postpartum support unfolds through deliberate initiatives and how it manifests in various forms of policies and practices. ${ }^{26}$ An in-depth exploration of postpartum support requires gathering and convergence of data from multiple sources, a hallmark of case study research. ${ }^{26}$ As such, multiple data collection methods, including (1) in-depth individual interviews (IDIs), (2) focus groups and (3) document review will be used in this study. A detailed description of Mothercraft Ottawa is provided in online supplemental appendix A.

In table 2, each dimension of the RE-AIM framework outlines what measures are proposed to address each dimension, define the data sources to be used and the corresponding RQs that will be addressed.

\section{Participant recruitment}

Postpartum mothers will be recruited by members of the research team (not affiliated with the Mothercraft organisation ( $\mathrm{ZJ}, \mathrm{AJ}, \mathrm{JE})$ ) who will present the study during the scheduled programme meetings. Due to the drop-in nature of these programmes and the variability in weekly attendance, four brief project introduction presentations will be carried out on two consecutive Mondays and two consecutive Thursdays. Partners of participants will similarly be recruited during regular attendance of a separate support drop-in programme. During recruitment, an information letter providing details about the study will be shared with participants and partners who will then decide whether they are interested in participating. The information letter will also be displayed in public areas at Mothercraft Ottawa's two locations. If interested, the information letter will direct them to contact study team members who will obtain consent and assess availability for an IDI. Once each IDI has been conducted, each participant will be given the letter of information to share with other mothers who may want to be involved in the programme. Eligible persons who receive this information and are interested in participating will be asked to contact the research team to arrange for more information, consent to participate, then complete their own IDI. The knowledge user and Co-principal Investigator (AA) will provide a list of key stakeholders and community partners affiliated with Mothercraft Ottawa programmes, and the project team members will identify potential participants representing diverse backgrounds to ensure maximum variation in the sample. This will include mothers, their family members, providers, community members and decision-makers representing administration, frontline/point of care and middle management levels.

Research team members will review the consent form with the interested participants, section by section and encourage them to ask questions. All questions about the study will be answered before the commencement of IDIs and focus group discussions (FGDs) and participants will be reminded that participation in this study is voluntary. Written consent will be obtained by a research team member. Paper copies of participant contact information during recruitment will be stored in a locked cabinet separate from other research data at the University of Ottawa in the principal investigator's office. This information will 
Table 2 RE-AIM dimensions, definitions, measures to be taken, data sources and research questions addressed

\begin{tabular}{|c|c|c|c|c|}
\hline RE-AIM dimension & Definition & $\begin{array}{l}\text { Activities and } \\
\text { measures }\end{array}$ & Data sources & RQs addressed* \\
\hline Reach & $\begin{array}{l}\text { The number and } \\
\text { representativeness of people } \\
\text { willing to participate in the } \\
\text { programme (ie, those most at } \\
\text { risk), and those that use the } \\
\text { services regularly. }\end{array}$ & $\begin{array}{l}\text { Demographic data } \\
\text { Postal code data } \\
\text { (descriptive, geospatial } \\
\text { analyses and regression } \\
\text { modelling) }\end{array}$ & $\begin{array}{l}\text { Demographic } \\
\text { questionnaire (IDI } \\
\text { participants only) } \\
\text { Participant sign-in } \\
\text { sheets }\end{array}$ & RQs 5-10 \\
\hline Implementation & $\begin{array}{l}\text { Is the programme } \\
\text { implemented consistently } \\
\text { over time? What are the costs } \\
\text { associated in the delivery of } \\
\text { the programme? } \\
\text { Do participants gain any } \\
\text { coping skills/strategies } \\
\text { as a result of programme } \\
\text { participation that they use on } \\
\text { a regular basis? }\end{array}$ & $\begin{array}{l}\text { Postal code data } \\
\text { (descriptive analyses) } \\
\text { IDls and FGDs with } \\
\text { participants and key } \\
\text { stakeholders } \\
\text { IDIs and FGDs with } \\
\text { participants and } \\
\text { partners }\end{array}$ & $\begin{array}{l}\text { Participant sign-in } \\
\text { sheets } \\
\text { IDI and FGDs transcripts } \\
\text { IDI and FGDs transcripts }\end{array}$ & $\begin{array}{l}\text { RQs } 2,4 \text { and } 5 \\
\text { RQs } 2 \text { and } 3\end{array}$ \\
\hline
\end{tabular}

${ }^{*}$ Refer to table 1 for the full list of research questions (RQs).

FGD, focus group discussion; IDIs, in-depth information interviews; RQ, research question.

be transcribed within 48 hours into a password-protected document after which the hard copies will be destroyed. Team members will sign a confidentiality agreement to maintain anonymity of study participants' information.

\section{In-depth individual interviews and focus group discussions}

Once participants have consented to participate, the research team will organise and conduct between 10 and 15 IDIs with key stakeholders; 3-5 postpartum programme users, 3-5 partners or 'significant others' of the women who have used the services and between 3 and 5 social and health services providers who have been involved in the programme including those who facilitate programme activities. Interview guide questions for each of the three stakeholder groups are provided in (online supplemental appendices B-D).

As noted by Patton, ${ }^{27}$ 'trustworthiness, meaningfulness, and insights generated from qualitative inquiry have more to do with the information-richness of the cases selected and the observational/analytical capabilities of the researcher than with sample size'. Purposive sampling strategy supported by a snowball technique will be used to select information rich cases. ${ }^{28}$ The snowball technique refers to the use of existing participants to share study information with other potential participants who may contact study team to enrol them in the study. ${ }^{2728}$ With this in mind, the final sample size will be determined by data 
saturation, that is, when no new data, ideas or concepts are generated from further data collection. ${ }^{29}$ It is to be noted that previous studies have shown that a sample size of at least 12 participants is generally adequate to reach data saturation. ${ }^{30} 31$

In this study, participants will be purposively selected to maximise variation or heterogeneity of the sample. Maximum variation sampling can be used by qualitative researchers to purposively different participants, units or case that maximise the diversity relevant to the research question. ${ }^{32} 33$ We sought to recruit first time mothers, participants with more than child, same-sex couples, as well as individuals of diverse socioeconomic status and age.

Semistructured IDIs are the most appropriate for the study as it ensures that significant questions posed by the study are addressed, while allowing for participant's views and perspectives to be revealed through an open-ended facilitation of discussion ${ }^{34}$ and processes not directly observable to emerge.$^{35}$ Field notes taken during interview would also be source of data. These field notes will capture direct observations of participants during a given data collection interaction.

All individuals who complete IDIs will be asked to take part in separate one-and-a-half-hour FGDs. The FGDs will be used as platform to share preliminary study findings with participants and solicit input into the data interpretation by the study team. One FGD will comprise programme participants (FGD1), their partners (FGD2), as well as care providers and stakeholders (FGD3). Stakeholders refer to decision-makers and knowledge users who have an influence on the Mothercraft programme and may use the study results to inform future programme planning. They include administrators, physicians and other managers from the Local Integrated Health Network who may not have participated in the IDIs, but may choose to attend a FGD. These individuals will be identified through purposive sampling supported by the snowball technique as described previously.

Each FGDs will be audio recorded and transcribed verbatim. They will take place at a Mothercraft Ottawa site. Sample sizes of between 6 and 10 participants per FGD have been shown to be adequate in helping researchers gain a comprehensive picture of issues influencing programme utilisation. ${ }^{36}$ These focus groups will serve as member check. In qualitative research, member check, also known as participant feedback, is a method used by researchers to help improve the trustworthiness of the data or establish the credibility of a study. ${ }^{20}{ }^{29}$ In this study, we will use it to solicit participants' input and feedback on the researchers' interpretation of their stories. All interview audio files be downloaded onto an encrypted and password-protected computer and deleted from the audio recorder once transferring has been complete. Notes will be taken by the research assistant (ZJ) who will work with the team during each FGD to guard against loss of information should the recording be interrupted. Additionally, observations of non-verbal communication (ie, facial expressions or body gestures) will be recorded. Again, the final sample size will be determined by data saturation. $^{37}$

During the IDIs and FGDs, participants will not be required to disclose their real names and may use a pseudonym during the discussion if they wish. IDI and FGD data collected from audio files will be transcribed by a professional transcriptionist. These files will be password-protected documents using word processing software with identifiable information removed. Once transcriptions are completed and checked/confirmed for accuracy by team members (ZJ, AJ and JE), their content will be analysed using thematic analysis. ${ }^{29}{ }^{38}$ Qualitative data analysis software (NVivo V.11) will be used to facilitate data analysis, storage and management.

Audio files will be stored on password-protected electronic devices that will only be used by the research team. When not in use, the devices will be stored in locked cabinets in a secured office at the academic research site that is only accessible to members of the research team.

\section{Document review}

Stake $^{26}$ defines document review as a data collection strategy that can be used to provide further context for the overall case. Document review is a key feature in case study research and will be conducted simultaneously with IDIs to triangulate/corroborate and augment information gained from interviews and to guide further areas of inquiry. ${ }^{29}{ }^{39}$ Formal documents often provide insight into an organisation's cultural and historical context, as well as technical operations. ${ }^{40}$ Consequently, we will review the content of purposefully selected historical articles dated between 2013 (inception year of the postpartum drop-in programme) and present that pertain to Mothercraft Ottawa. Eligible documents for review include (1) job descriptions, (2) policy documents (eg, for decisionmaking and position statements regarding postpartum programmes), (3) strategic plans, (4) annual reports and (5) meeting minutes. We will also collect and analyse the content of relevant (6) meeting notes, (7) content identified on social media platforms (eg, Facebook), and (8) newspapers articles. Access to most of these documents will be facilitated by the knowledge user/Co-primary Investigator (AA) who is located at Mothercraft Ottawa.

The document review, which will help address research questions 1-3 (see tables 1 and 2), will be an iterative process, and decisions about the number and types of documents to be reviewed will be guided by data collected from participant interviews and accessibility to documents. Data extraction will be guided by a document summary form recommended by Miles and Huberman. ${ }^{41}$ Once completed, extracted data will be imported into NVivo V.10 qualitative data analysis software to assist with coding, data management and storage.

\section{Data analysis}

Qualitative data from IDIs and FGDs will be audio recorded and transcribed verbatim. Our team will follow the six-step framework for thematic analysis as described by Braun and 
Clarke. ${ }^{38} \mathrm{~A}$ theme is a pattern identified in the information that describes and organises the possible observations or interpretations of phenomena identified in the data. This process will begin with the development of a coding framework informed by questions from the interview guides and will involve a systematic approach that includes: (1) data familiarisation; (2) generating initial codes; (3) identifying themes; (4) reviewing, defining and naming themes; (5) interpreting the narratives and stories; and (6) producing the report-a concise, coherent, logical and non-repetitive account supported by vivid examples. ${ }^{38} 42$ NVivo qualitative data analysis software will be used to facilitate data categorisation, storage and management. Reflective team meetings will be carried out to establish impressionistic views of the data and in an effort to gain detailed insights from the individual team members' analyses. Preconceptions and assumptions will be challenged, and a consensus will be reached in understanding the data.

\section{Trustworthiness of data}

We will employ Lincoln and Guba's ${ }^{43}$ quality criteria for developing trustworthiness in qualitative research, which will guide our data validation method. In this research, transparent analytical steps have been identified and informed by established qualitative research principles. Transcripts will be carefully verified and checked for accuracy and completeness. In the analysis process, special attention will be paid to misrepresentation of the data and we will interrogate the data until data saturation is reached. Furthermore, research team members have expertise conducting ethical and sensitive research with postpartum women. Transferability of the data will be dependent on 'thick description', which in this work entails a detailed and precise narrative that will be constructed following a thorough analysis of the data. The narrative description will provide sufficient detail for others to make a judgement on the quality of the findings. Confirmability will be achieved by reflexive team meetings. Dependability will be achieved by establishing a clear audit trail and accurate documentation of the research processes and procedures, including the analytical process, field notes, digital recordings and copies of transcriptions.

\section{Study phase II: demographic questionnaire, regression modelling, and geospatial analysis}

All programme participants who agree to participate in the IDIs will be asked to complete a demographics questionnaire prior to their interview (see Appendix E). This questionnaire was designed to gather a variety of social and economic factors (eg, current age, place of birth of last child, race/ethnicity, relationship, and employment status, and estimated total income) information about the participant. Results of the demographics questionnaire (administered only to IDI participants) will be summarised numerically using descriptive statistics (eg, means, SD, frequencies and percentages) by $\mathrm{AJ}$ and $\mathrm{KE}$ using R statistical software V.3.6.0, or narratively, as appropriate.

Each time an individual attends a programme session, their residential postal code is collected by the programme facilitator during the 'sign-in' process. These data, which are summarised according to session date and programme location, will be analysed to gain a greater understanding of programme implementation and reach (see table 2) using the methodology described in the sections that follow.

\section{Data analysis}

\section{Descriptive analyses}

Postal code data (obtained from all participants at the start of each programme session) will first be analysed using descriptive statistics by $\mathrm{AJ}$ and $\mathrm{KE}$ (R V.3.6.0) to gain a greater understanding of programme attendance and patterns of attendance over time. Each unique postal code will represent the number of times a participant attended the programme with identical postal codes representing the same participant over time. Data from the mothers' (two locations) and partners' (one location) programmes will be analysed separately. Specific items to be addressed include: (1) the average number of times participants attend the programme, (2) trends in attendance, such as seasonal preference or day of the week, (3) increases or decreases in attendance over time and (4) differential attendance by programme location.

\section{Geospatial analyses}

Following descriptive analyses described above, postal codes will be mapped in ArcGIS V.10.6 and a geospatial analysis will be completed by $\mathrm{KE}$, to assess the average distance participants travelled to attend the programme. First, all postal codes will be converted to latitude and longitude coordinates using the publicly available Statistics Canada postal code conversion file. ${ }^{44}$ Access to services will be calculated using the distance between where a participant lives and the location of the programme attended. ${ }^{45}$ Postal code data will also be aggregated to census tract boundaries, ${ }^{46}$ which typically have a population of 2500 and 8000 persons. Analyses will be conducted separately for each programme location and will assume that all participants leave from their homes to attend the programme. The results will be summarised in spatial density maps and described narratively.

\section{Regression modelling}

Individual-level sociodemographic variables are not available for all programme participants. As such, we will attempt to gain an understanding about what characteristics are associated with programme attendance within census tract boundaries (described previously). Specifically, each postal code will be spatially linked to census tract level socioeconomic (eg, median household income) and demographic variables (eg, race, age, primary language spoken) from the 2016 Canadian Census, available from Statistics Canada. ${ }^{47}$ Poisson regression will then be carried out to assess which of these census tract characteristics are associated with the number of participants who attend programmes from each census tract. The log number of women of childbearing age (15-49) will be used as an offset in the model, and the distance between the census tract centroid and programme centres will be 
included to control for the effect of proximity. Final model selection will be conducted using a forward stepwise method by entering variables that have the highest non-parametric correlation (Spearman's rank) with participant counts from each census tract. The best model will be selected using the Akaike Information Criterion; residuals will be examined to ensure that model assumptions are met. Conclusion drawn from analyses based on aggregate data (ie, at the census-tract level, such as those proposed here) is vulnerable to ecological fallacy. ${ }^{48}$ As such, our findings will be interpreted with the assumption that any associations identified between explanatory variables and programme attendance may not be directly applicable to individuals.

\section{Confidentiality}

The demographics questionnaire contains personal information; thus, special care will be given protect the confidentiality of participants. Pseudonyms will be used to code files and all documents will be stored in a separate file and locked cupboard accessible only to the research team. Furthermore, only research team members conducting FGDs and IDIs and geospatial analyses will have access to participant names and postal codes, which will be kept in a secure location and will not be disclosed to anyone else. Specifically, spreadsheets containing postal code information will be passwordprotected and no one outside of the study group will be provided access to the data. Names and personal identifiers will not be used on study materials; once participants agree to participate in the study, they will be identified by a research code (eg, MPPE 001). Before research findings are made publicly available, the results will be aggregated to ensure no individual can be identified. Geospatial analyses may be completed at the postal code level but will be presented as an aggregated area to protect the identity of study participants.

\section{ETHICS AND DISSEMINATION}

Ethics approval was granted by the Research Ethics Board at the University of Ottawa (H-12-18-1492). The research process adheres to the ethical standard of the Tri-Council Policy-2 $2^{29}$ and participants will give free and informed consent according to the TCPS 2: Ethical Conduct for Research Involving Humans. ${ }^{49}$ FGD participants have been informed via the information letter, that group participation precludes concealment of their identity and enhanced risks for a breach of confidentiality to the information shared in group. Participants will also be informed, however, that while all participants may agree to keep matters discussed by the group in confidence, there is the risk that some people may not honour the agreement.

Several steps will be taken to protect participants' confidentiality include: (1) assigning pseudonyms thereby removing identifying information from documents, (2) the list of participant names will be kept separate from the data collected, (3) interviews will be conducted in mutually agreed on place of privacy, (4) participants will be reminded that they are free to refuse to answer any questions, and (5) access to the raw data will be limited to investigators, trainees and transcriptionist. Mothercraft Ottawa has been informed that the organisation will not be kept anonymous in research reports or publications about this study.

\section{Study phase III: knowledge translation and exchange}

In study phase III, we will share our results with multiple audiences (eg, research/policy sphere and local service delivery organisations) in a variety of formats, including a final report of the findings, in an academic thesis, at academic conferences, and in peer-reviewed publications. Results will also be presented to decision-makers, service providers and programme users at information workshops.

The planned end-of-project knowledge translation event, which will include FGDs, will gain insight into the lived experiences of the participants and other stakeholders to make sense of the research results from IDIs, document review, sociodemographic and geospatial analysis. The main goal of this study phase is to generate evidence-informed recommendations to strengthen or scale up the Mothercraft postpartum support programme. These knowledge translation strategies are intended to serve as a process of colearning and cocreation of knowledge to inform the development of postpartum support programmes in other jurisdictions.

Mothercraft Ottawa intends to use the results of this study to: (1) validate programme strengths and maintain the critical programme components; (2) modify the programme to address gaps and emphasise its strengths; (3) support funding applications for sustainable programme expansion to serve a broader clientele across a greater geography within Ottawa, and (4) inform the development of a comprehensive service expansion of a broader perinatal mental health programme.

Acknowledgements The authors wish to thank all key stakeholders, programme participants, partners and social/health services providers who have agreed to participate in the study.

Contributors All authors drafted the manuscript. JE, AJ and AA conceived the study and all authors critically reviewed and revised the manuscript. All authors read and approved the final manuscript.

Funding The authors have not declared a specific grant for this research from any funding agency in the public, commercial or not-for-profit sectors.

Competing interests Alicia Ashton is the Executive Director of Mothercraft Ottawa but will have no direct involvement in data collection or analysis. As a study that follows the tenets of community-based participatory research, involvement of those being studied (ie, organisational leadership) is critical to shared ownership and uptake of results to improve future programming. All other authors report no competing interests.

Patient and public involvement Patients and/or the public were involved in the design, or conduct, or reporting, or dissemination plans of this research. Refer to the Methods section for further details.

\section{Patient consent for publication Not required.}

Provenance and peer review Not commissioned; externally peer reviewed.

Open access This is an open access article distributed in accordance with the Creative Commons Attribution Non Commercial (CC BY-NC 4.0) license, which permits others to distribute, remix, adapt, build upon this work non-commercially, and license their derivative works on different terms, provided the original work is properly cited, appropriate credit is given, any changes made indicated, and the use is non-commercial. See: http://creativecommons.org/licenses/by-nc/4.0/.

ORCID iD

Amy Johnston http://orcid.org/0000-0003-1934-7867 


\section{REFERENCES}

1 Anderson FM, Hatch SL, Comacchio C, et al. Prevalence and risk of mental disorders in the perinatal period among migrant women: a systematic review and meta-analysis. Arch Womens Ment Health 2017;20:449-62.

2 Gavin NI, Gaynes BN, Lohr KN, et al. Perinatal depression: a systematic review of prevalence and incidence. Obstet Gynecol 2005;106:1071-83.

3 Hoffman C, Dunn DM, Njoroge WFM. Impact of postpartum mental illness upon infant development. Curr Psychiatry Rep 2017;19:100-00.

4 Misri S, Kendrick K. Treatment of perinatal mood and anxiety disorders: a review. Can J Psychiatry 2007;52:489-98.

5 Ross LE, McLean LM. Anxiety disorders during pregnancy and the postpartum period: a systematic review. J Clin Psychiatry 2006;67:1285-98.

6 van der Zee-van den Berg Al, Boere-Boonekamp MM, IJzerman MJ, et al. Screening for postpartum depression in well-baby care settings: a systematic review. Matern Child Health J 2017;21:9-20.

7 Rai S, Pathak A, Sharma I. Postpartum psychiatric disorders: early diagnosis and management. Indian J Psychiatry 2015;57:S216-21.

8 Zauderer C. Postpartum depression: how childbirth educators can help break the silence. J Perinat Educ 2009;18:23-31.

9 WHO. Maternal mental health World Health organization, 2019. Available: https://www.who.int/mental health/maternal-child/ maternal_mental_health/en/ [Accessed 30 Jul 2019].

10 Statistics Canada. Maternal mental health in Canada Ottawa. Ontario, 2019. https://www150.statcan.gc.ca/n1/en/pub/11-627-m/11-627m2019041-eng.pdf?st=GX8fjqUZ

11 Marcus SM, Flynn HA, Blow FC, et al. Depressive symptoms among pregnant women screened in obstetrics settings. $J$ Womens Health 2003;12:373-80.

12 Pearlstein T, Howard M, Salisbury A, et al. Postpartum depression. Am J Obstet Gynecol 2009;200:357-64.

13 Biaggi A, Conroy S, Pawlby S, et al. Identifying the women at risk of antenatal anxiety and depression: a systematic review. J Affect Disord 2016;191:62-77.

14 Kantrowitz-Gordon I. Internet Confessions of postpartum depression issues in mental health nursing. , 2010: 2013, 874-82.

15 CMNRP. Mapping the Maternal-Newborn care spectrum in the Champlain and South East LHINs: final report and recommendations. 40, 2017.

16 Tariq S, Woodman J. Using mixed methods in health research. JRSM Short Rep 2013;4:204253331347919.

17 Re-aim. Frequently asked questions: Re-aim, 2019. Available: http:// www.re-aim.org/about/frequently-asked-questions/ [Accessed Mar 2019].

18 Glasgow RE, Vogt TM, Boles SM. Evaluating the public health impact of health promotion interventions: the RE-AIM framework. Am J Public Health 1999:89:1322-7.

19 Minkler M, Blackwell AG, Thompson M, et al. Community-Based participatory research: implications for public health funding. Am J Public Health 2003;93:1210-3.

20 Etowa JB, Bernard WT, Oyinsan B, et al. Participatory action research (PAR): an approach for improving black women's health in rural and remote communities. J Transcult Nurs 2007;18:349-57.

21 Etowa J, Matthews V, Vukic A, et al. Uncovering Aboriginal nursing knowledge through community based participatory research (CBPR). Int Indig Policy J 2011;22:1-16.

22 Holkup PA, Tripp-Reimer T, Salois EM, et al. CommunityBased participatory research. Advances in Nursing Science 2004;27:162-75.

23 Freire P. Pedagogia do Oprimido. Rio de Janeiro: Paze Terra, 1970.

24 Kemmis S, McTaggart R. Participatory Action Research: Communicative Action and the Public Sphere. In: Denzin N, Lincoln
Y, eds. The Sage handbook of qualitative research. 3rd ed. Sage Publications, 2005.

25 McNiff J, Whitehead J. All you need to know about action research. Thousand Oaks, CA: Sage, 2006.

26 Stake R. The art of case study research. Thousand Oaks: Sage Publications Inc, 1995.

27 Patton M. Qualitative evaluation and research methods. 2nd ed. Newbury Park, CA: Sage Publications, 1990.

28 Ezzy D. Qualitative analysis: practice and innovation. crows nest. NSW: Allen \& Unwin, 2002.

29 Creswell J, Poth C. Qualitative inquiry and research design choosing among five approaches. 4th ed. Thousand Oaks: Sage Publications, Inc, 2018.

30 Lasch KE, Marquis $\mathrm{P}$, Vigneux M, et al. Pro development: rigorous qualitative research as the crucial Foundation. Qual Life Res 2010;19:1087-96.

31 Onwuegbuzie A, Leech N, Collins K. Innovative data collection strategies in qualitative research. Qual Res 2010;15:696-726.

32 Morse JM. Editorial: determining sample size. Qual Health Res 2000;10:3-5.

33 Sandelowski M. Sample size in qualitative research. Res Nurs Health 1995;18:179-83.

34 Pope C, Mays N. Qualitative Interviews. In: Qualitative research in health care, 2006: 12-20.

35 McEvoy P, Richards D. A critical realist rationale for using a combination of quantitative and qualitative methods. Nurs Res 2006;11:66-78.

36 Guest G, Namey E, McKenna K. How many focus groups are enough? building an evidence base for Nonprobability sample sizes. Field methods 2017;29:3-22.

37 Saunders B, Sim J, Kingstone T, et al. Saturation in qualitative research: exploring its conceptualization and operationalization. Qual Quant 2018;52:1893-907.

38 Braun V, Clarke V. Using thematic analysis in psychology. Qual Res Psychol 2006;3:77-101.

39 Yin R. Case study research design and methods. 282. Thousand oaks,CA: Sage, 2014.

40 Bryman A. Social research methods. 2nd ed. New York: Oxford University Press, 2004

41 Miles M, Huberman A. Qualitative data analysis: an expanded sourcebook. 2nd ed. Thousand Oaks, CA: Sage Publications, Inc, 1994.

42 Clarke V, Braun V. Teaching thematic analysis: overcoming challenges and developing strategies for effective learning. Psychologist 2013;26:120-3.

43 Lincoln YS, Guba EG, Pilotta JJ. Naturalistic inquiry. Newbury Park, CA: Sage, 1985: 9. 438-9.

44 Statistics Canada. Postal code conversion File.Statistics Canada, 2019. Available: https://www150.statcan.gc.ca/n1/en/catalogue/92154-X[Accessed 15 Mar 2019].

45 Statistics Canada. Road network files: statistics Canada, 2018. Available: https://www12.statcan.gc.ca/census-recensement/2011/ geo/RNF-FRR/index-eng.cfm [Accessed 15 Mar 2019].

46 Statistics Canada. Dissemination area boundary Files.Statistics Canada, 2019. Available: https://www150.statcan.gc.ca/n1/en/ catalogue/92-169-X [Accessed 15 Mar 2019].

47 Statistics Canada. Data products census: statistics Canada, 2019. Available: https://www12.statcan.gc.ca/census-recensement/2016/ dp-pd/index-eng.cfm [Accessed 15 Mar 2019].

48 Saunders C, Abel G. Ecological studies: use with caution. Br J Gen Pract 2014;64:65-6.

49 Panel on Research Ethics TCPS 2. CORE- tutorial: government of Canada, 2019. Available: https://tcps2core.ca/welcome [Accessed 21 Dec 2019]. 